\title{
O estudo dos heterogenéricos, heterossemânticos e heterotônicos como aceleradores do processo ensino-aprendizagem do idioma espanhol para os acadêmicos de um curso de Letras.
}

\author{
Moisés Sarapion Silveira \\ Rua topázio, 1664. Bairro $\mathrm{N}^{\text {sa }}$. $\mathrm{S}^{\text {ra }}$. de Lourdes. Cep. 38035-220 - Uberaba - Mg. \\ Tel 3315-0644 - e-mail: moisessarapion@mednet.com.br \\ Faculdades Associadas de Uberaba - Fazu
}

RESUMO: O presente trabalho originou-se a partir da constatação de que a maioria dos acadêmicos do curso de Letras Português / Espanhol, de uma faculdade privada de Uberaba - MG, não teve nenhum, ou "quase nenhum" estudo acerca da Língua Estrangeira (LE) na qual pretende atuar como docente. Assim, foram pesquisados os trinta e quatro acadêmicos do curso de Letras Português / Espanhol dessa faculdade, divididos nos sete períodos do curso, durante o primeiro semestre de 2007. A partir da análise dos dados obtidos na pesquisa, propôs-se como problema que a maioria dos acadêmicos teria, pelo fato de não haver estudado o idioma espanhol anteriormente, apenas o período que compreende a duração do curso de graduação para deixar uma "zona de total ou quase total desconhecimento" acerca do idioma espanhol e atingir uma "zona de conhecimento" que Ihes possibilitasse a atuação como docente em Língua Estrangeira (LE). Diante disso, propõe-se o ensino dos heterogenéricos, heterossemânticos e heterotônicos como aceleradores, no início do processo ensinoaprendizagem. Essa proposta visa a trabalhar as semelhanças e as diferenças existentes entre os dois idiomas, uma vez que se pode constatar, na literatura especializada, a grande proximidade existente entre os idiomas português e o espanhol.

Palavras-chave: Heterogenéricos. Heterossemânticos. Heterotônicos.

The study of the heterogeneric, heterosemantic and heterotonic words as accelerators of the Spanish language teaching-learning process for the students of a Letters course

ABSTRACT: The present work started from the verification, through research, that most of the academics of the Letras Português / Espanhol (Portuguese and Spanish Letters) course, of a private college from Uberaba - MG, didn't have any, or "almost any" study about the foreign language (FL) in which intends to act as educational. Before that fact, it was delimited as researched public that compound by the academics of the Letras Português / Espanhol course of that college, completing a total of 34 academics, divided in the seven periods of the course, during the first semester of 2007. Starting from the analysis of the data obtained in the research, it has proposed as problem that most of the academics would have, for the fact of having not studied the Spanish language previously, just the period that comprehends the duration of the degree course to leave an "area of total or almost total ignorance" concerning the Spanish language and to reach a "knowledge zone" that made them possible the performance as educational in foreign language (FL). Thus, one proposes the teaching of the heterogeneric, heterosemantic and heterotonic words as accelerators, in the beginning of the process teaching-learning. That proposal seeks to work the similarities and the existent differences among the two languages, once one can verify, in the specialized literature, the great existent proximity between the Portuguese and Spanish languages.

Keywords: Heterogeneric. Heterosemantic. Heterotonic. 


\section{INTRODUÇÃO}

O interesse pelo estudo do espanhol ${ }^{1}$ como Língua Estrangeira (E/LE) cresce a cada dia, não apenas em nosso país, mas também em todo o mundo.

O espanhol é a língua oficial de vinte e dois países. Além disso, é também o idioma oficial de importantes órgãos internacionais como: ONU (Organização das Nações Unidas), UE (União Européia), UNESCO ${ }^{2}$ (Organização das Nações Unidas para a Educação, Ciências e Cultura), MERCOSUL (Mercado Comum do Sul).

Apesar de existir uma variação nos dados, dependendo da fonte consultada, sabe-se que o idioma espanhol conta atualmente com mais de 400 milhões de falantes nativos e mais de 100 milhões de falantes estrangeiros, espalhados por todos os continentes.

No Brasil, o aumento das relações comerciais com os nossos vizinhos sulamericanos, em sua grande maioria falante do espanhol; a criação e implantação do Mercosul; entre outros fatores, desencadearam uma grande procura, por parte de trabalhadores e empresários de diversas áreas, pela aprendizagem da língua espanhola.

Por outro lado, a implementação da Lei $n^{\circ} 11.161$, de 05 de agosto de 2005, que institui a obrigatoriedade da implantação do ensino do espanhol como Língua Estrangeira (LE) nas escolas de ensino médio, tanto da rede pública quanto da rede privada até 2010, oportunizou uma enorme demanda por professores de E/LE.

Segundo estudos realizados pelo Ministério da Educação e Cultura - MEC será necessário, inicialmente, cerca de 13.200 profissionais para atender às exigências da lei. Tal fato irá, seguramente, refletir nas faculdades, centros universitários e universidades, no que diz respeito à procura pela formação docente em língua espanhola.

Este trabalho tem como objetivo propor uma metodologia de ensino da língua espanhola para falantes do português do Brasil, que acelere o processo ensinoaprendizagem e que minimize a sensação de desconforto do aluno, em relação ao aprendizado do espanhol como Língua Estrangeira, utilizando, para isso, o conhecimento do aluno em sua Língua Materna (LM).

Assim, propõe-se o ensino dos heterogenéricos, heterossemânticos e heterotônicos como aceleradores, no início do processo ensino-aprendizagem. Essa proposta visa a trabalhar as semelhanças e as diferenças existentes entre os dois idiomas, uma vez que se pode constatar, na literatura especializada, que o português e o

Espanhol e Língua Espanhola serão tratados como sinônimos.

O termo UNESCO significa em inglês: United Nations Educational, Scientific and Cultural Organization. 
espanhol "são o par de línguas latinas mais próximas" (RODRIGUES apud FIALHO, 2005).

Portanto, acredita-se que o estudo e a internalização desses vocábulos, no início do processo ensino-aprendizagem, podem atuar de forma significativa no desenvolvimento do aluno, pois a partir deles o estudante será capaz de realizar, de maneira correta, as suas próprias escolhas no idioma estrangeiro. Assim, o aluno poderá situar-se em uma "zona de confiança" capaz de impulsioná-lo e motivá-lo para a aprendizagem do idioma espanhol.

\section{ASPECTOS METODOLÓGICOS}

O presente trabalho originou-se a partir da constatação, por meio de pesquisa, de que a maioria dos acadêmicos do curso de Letras Português / Espanhol, de uma faculdade particular de Uberaba - MG, não teve, antes de iniciar o curso de graduação, nenhum ou "quase nenhum" contato com a Língua Estrangeira (LE), na qual pretende atuar como docente.

Diante desse fato, delimitou-se como público pesquisado aquele composto pelos acadêmicos do curso de Letras Português / Espanhol dessa faculdade privada, perfazendo um total de 34 acadêmicos, divididos nos sete períodos do curso, durante o primeiro semestre de 2007.

Desse modo, propôs-se como problema que a maioria dos acadêmicos teria, pelo fato de não haver estudado o idioma espanhol anteriormente, apenas o período que compreende a duração do curso de graduação para deixar uma "zona de total ou quase total desconhecimento" acerca do idioma espanhol e atingir uma "zona de conhecimento" que lhe possibilitasse a atuação como docente em Língua Estrangeira (LE).

Gerou-se, então, como hipótese que o estudo e a internalização dos vocábulos heterogenéricos, heterossemânticos e heterotônicos pelos acadêmicos podem acelerar o processo ensino-aprendizagem do idioma espanhol devido à proximidade existente entre os idiomas português e espanhol.

Além disso, verificou-se, por meio de pesquisa bibliográfica, que a grande maioria do material didático voltado para o ensino da língua espanhola para os falantes do português do Brasil aborda o estudo desses vocábulos; embora se reconheça que, em alguns casos, a abordagem realizada situa-se em um campo apenas superficial, priorizando, simplesmente, o lado cômico de algumas situações.

Assim, o objetivo deste trabalho é propor uma metodologia fundamentada na Análise Contrastiva e na Análise de Erros, que aproveite o conhecimento do acadêmico 
em sua Língua Materna (LM) e que acelere o processo ensino-aprendizagem do espanhol.

Propõe-se tal metodologia, uma vez que se considera como umas das principais, se não a principal finalidade de um curso de Letras, a preparação do acadêmico a fim de exercer a prática da docência, tanto em sua Língua Materna quanto na Língua Estrangeira por ele escolhida.

Assim sendo, o presente trabalho justifica-se pela possibilidade de estabelecer uma relação direta entre os estudos da LM e da LE; por propor uma provável reavaliação do material didático adotado; e pela possibilidade de essa metodologia ser utilizada nos Ensinos Superior e Médio.

Utilizou-se como método de abordagem o hipotético-dedutivo, no qual se formulou uma hipótese e se procurou, por meio da inferência dedutiva, testar a predição da ocorrência sugerida pela hipótese, para que se pudesse constatar ou não a sua veracidade.

Recorreu-se a três diferentes métodos de procedimento. Pela utilização do método de procedimento monográfico buscou-se aprofundar na literatura ligada ao tema para elaboração do arcabouço teórico da pesquisa.

Pelo uso do método de procedimento estatístico, procurou-se constatar, por meio do levantamento e da análise de dados, a faixa etária dos acadêmicos; a condição dos acadêmicos em relação ao conhecimento do idioma espanhol antes do início do curso de graduação; o tempo de estudo da língua espanhola daqueles que já haviam estudado esse idioma antes de ingressarem na faculdade; o número de acadêmicos que iniciaram os estudos em um curso de língua espanhola, após ingressarem na faculdade e, por último, o idioma no qual o acadêmico havia feito sua avaliação em Língua Estrangeira no exame vestibular.

Considerou-se, ainda, o método de procedimento funcionalista, pois o estudo poderia servir de referência e/ou como pesquisa futura, em relação ao processo ensinoaprendizagem do idioma espanhol na faculdade investigada.

As técnicas utilizadas referiram-se às pesquisas de natureza quantitativa e qualitativa, nas quais se empregaram técnicas de documentação indireta - pesquisa documental e bibliográfica. Além disso, utilizou-se a direta extensiva, por meio da aplicação de um questionário que foi respondido, por escrito, pelos acadêmicos.

O questionário foi elaborado com cinco perguntas fechadas e foi aplicado aos acadêmicos, pelo pesquisador, no período compreendido entre os dias 12 e 14 de março de 2007. 


\section{COLETA E ANÁLISE DOS DADOS}

Justifica-se a apresentação da coleta e da análise dos dados obtidos junto aos acadêmicos pesquisados neste ponto do trabalho, uma vez que a origem deste trabalho se deu a partir dos mesmos.

\subsection{A coleta dos dados}

A presente pesquisa foi elaborada com a finalidade de se conhecer o grau de conhecimento dos acadêmicos de uma faculdade privada de Uberaba - MG acerca do idioma espanhol antes de iniciarem o curso de graduação, uma vez que o resultado da análise dos dados seria extremamente importante para a proposição ou não de uma metodologia de ensino.

Diante desse fato, delimitou-se como público pesquisado aquele composto pelos acadêmicos do curso de Letras Português / Espanhol dessa instituição de ensino superior instalada na cidade de Uberaba - MG. Assim, foram pesquisados 34 acadêmicos $^{3}$, divididos nos sete períodos do curso, durante o primeiro semestre de 2007.

$\mathrm{O}$ questionário foi elaborado com cinco perguntas fechadas e foi aplicado aos acadêmicos pelo pesquisador, no período compreendido entre os dias 12 e 14 de março de 2007.

Os dados obtidos por meio do questionário ${ }^{4}$ foram tabulados e analisados, a fim de se conhecer a representação estatística dos mesmos. O referido instrumento de pesquisa apresentava as seguintes questões:

1- Favor informar faixa etária na qual está inserido (a).

2- Você já havia estudado a língua espanhola antes de iniciar o seu curso de graduação?

2.1 Caso a resposta anterior seja "não", favor responder à questão número $2.2 \mathrm{e}$, na seqüência, à questão número 3 . Caso a resposta, na questão número 2 , seja "sim", favor informar, abaixo, por quanto tempo você estudou a língua espanhola antes de iniciar a sua graduação, respondendo em seguida a questão número 3.

2.2 Após o início do seu curso de graduação, você começou a fazer algum curso de língua espanhola para complementar os seus estudos acerca desse idioma?

3- No exame vestibular, em qual idioma foi realizada a sua avaliação de Língua Estrangeira?

\footnotetext{
${ }^{3}$ O número total de acadêmicos que estudam o espanhol como Língua Estrangeira, no semestre pesquisado, é de 35 alunos. Por motivos óbvios, o pesquisador não respondeu ao questionário.

${ }^{4}$ O pesquisador preferiu não apresentar as opções de resposta junto ao questionário, uma vez que a análise dos dados permite ao leitor identificá-las.
} 


\subsection{Análise dos dados obtidos}

A análise dos dados obtidos na primeira pergunta do questionário mostrou que dentre os acadêmicos que participaram da pesquisa, respondendo ao questionário, seis por cento $(6 \%)$ estão situados na faixa etária dos dezoito aos vinte e um anos (18 a 21 anos), vinte e quatro por cento (24\%) dos vinte e dois aos vinte e cinco anos (22 a 25 anos), quinze por cento (15\%) dos vinte e seis aos trinta anos (26 a 30 anos), vinte e nove por cento (29\%) estão inseridos na faixa dos 31 aos 35 anos (31 a 35 anos) e vinte e seis por cento (26\%) dos acadêmicos têm mais de trinta e cinco anos (acima de 35 anos).

Optou-se por conhecer a faixa etária dos acadêmicos devido ao fato de que muitos investigadores do processo de aprendizagem de uma Língua Estrangeira acreditam na existência de um "período crítico".

"Aceita-se que existe um período crítico para a aprendizagem, ou seja, uma idade na qual a aprendizagem de uma L2 seja mais efetiva, esse período crítico está relacionado com a plasticidade e a maturação do cérebro" (GARGALLO, 1999, p. 25), (Tradução Nossa).

A partir da afirmativa anterior, percebe-se que o grau de dificuldade dos acadêmicos pesquisados em aprender uma LE torna-se muito maior, pois mais da metade dos entrevistados já passou dos vinte e seis (26) anos.

Por meio da segunda pergunta, procurou-se saber se os acadêmicos já haviam estudado a língua espanhola antes de iniciarem o curso de graduação. Verificou-se que $68 \%$ dos acadêmicos não haviam estudado a língua espanhola.

Observou-se, ainda, na questão 2.2, que oitenta e três por cento (83\%) dos acadêmicos que não haviam estudado o idioma espanhol antes de iniciarem o curso de graduação, tampouco haviam começado a fazer um curso de língua espanhola para complementar os estudos acerca desse idioma. Em contrapartida, dezessete por cento (17\%) daqueles que não haviam estudado a língua espanhola antes de iniciarem o curso de graduação, procuraram um curso particular para completar seus estudos em relação ao idioma estrangeiro, após ingressarem na faculdade.

A partir dos números anteriormente apresentados, percebe-se que a grande maioria dos acadêmicos estuda o espanhol como Língua Estrangeira apenas na faculdade.

A análise dos dados referentes à questão 2.1 mostrou que trinta e dois por cento (32\%) dos acadêmicos já haviam estudado a língua espanhola antes de iniciarem o curso de graduação. Dentre eles trinta e seis por cento (36\%) haviam estudado o idioma estrangeiro por um período que variava entre sete e doze meses (7 a 12 meses), nove por 
cento $(9 \%)$ haviam estudado o idioma espanhol entre treze e dezoito meses (13 a 18 meses), outros nove por cento ( $9 \%$ ) haviam estudado a língua espanhola entre dezenove e vinte e quatro meses (19 a 24 meses), enquanto que os quarenta e seis por cento (46\%) restantes haviam estudado o idioma espanhol, antes de iniciarem o curso de graduação, por um período maior que vinte e cinco meses (acima de 25 meses).

Na questão número 3 procurou-se verificar em qual idioma o acadêmico havia realizado a avaliação de Língua Estrangeira no exame vestibular. Constatou-se que oitenta e cinco por cento (85\%) dos acadêmicos realizaram sua avaliação de Língua Estrangeira no idioma espanhol. Dentre as respostas obtidas, essa foi, sem dúvida, a que mereceu maior atenção, visto que foi constatado que o percentual de acadêmicos que jamais havia estudado a língua espanhola e que mesmo assim realizou a prova de Língua Estrangeira do exame vestibular nesse idioma atingiu setenta e oito por cento ${ }^{5}(78 \%)$.

A partir da análise dos dados, percebe-se claramente que a maioria dos acadêmicos está numa faixa etária acima dos vinte e seis (26) anos, estuda a língua espanhola apenas na faculdade e que, mesmo sem nunca ter estudado a língua espanhola, realizou a avaliação de Língua Estrangeira, do exame vestibular, nesse idioma. Desse último fato pode-se inferir que os acadêmicos optaram pela língua espanhola por acreditarem que a semelhança existente entre o português e o espanhol poderia garantir-lhes um melhor rendimento no exame vestibular.

A partir dessas constatações e considerando-se, ainda, que uma das principais, se não a principal finalidade de um curso de Letras é preparar o acadêmico para que possa exercer a prática da docência tanto em sua Língua Materna quanto na Língua Estrangeira, julgou-se oportuno o desenvolvimento de um trabalho que pudesse propor uma metodologia de ensino capaz de conciliar a utilização do conhecimento que o acadêmico possui em sua LM e o pouco tempo que terá para transitar de um ponto de "quase" total desconhecimento acerca da língua espanhola para uma posição de mediador no ensino dessa língua.

\section{FUNDAMENTAÇÃO TEÓRICA}

Neste ponto do trabalho pretende-se apresentar os aspectos históricos, geográficos e políticos relativos à proximidade existente entre os idiomas português e espanhol. Pretende-se, ainda, apresentar ao leitor informações acerca da Análise

\footnotetext{
Não faz parte dos objetivos deste trabalho questionar o exame vestibular ou, ainda, a maneira como o aluno conseguiu sua aprovação no mesmo, sem jamais ter estudado o espanhol como Língua Estrangeira.
} 
Contrastiva e da Análise de Erros, bem como o estudo sobre os vocábulos heterogenéricos, heterossemânticos e heterotônicos.

\subsection{Os aspectos histórico, político e geográfico da proximidade entre o português e o espanhol}

A proximidade entre os idiomas português e espanhol não está relacionada apenas e simplesmente ao fato de ambas as línguas terem uma origem (neo) latina. Pode-se, ainda, acrescentar a isso pelo menos outros dois fatores que cooperaram para essa proximidade: o aspecto geográfico e, sem dúvida, o Domínio Filipino, que representa os 60 anos, compreendidos entre 1580 e 1640, durante os quais Portugal viveu sob o domínio espanhol.

As línguas neolatinas, expressão utilizada para denominar os idiomas que surgiram a partir do latim vulgar ${ }^{6}$, originaram-se a partir da expansão do Império Romano. Desse modo, o latim, que até então era falado apenas na região do Lácio, atual Roma, estendeu-se por toda a Europa Ocidental.

A cada conquista territorial, os romanos impuseram o idioma latino aos povos conquistados, sendo que o latim, por sua vez, recebeu também a influência dos idiomas falados nessas regiões. A partir dessa mistura, originaram-se vários dialetos. Alguns deles acabaram desaparecendo, enquanto outros se estruturaram e deram origem às línguas neolatinas. Destacam-se entre as línguas neolatinas: o português, o espanhol, o italiano, o francês, o provençal, o galego, o ladino ou rético e o romeno.

Outro aspecto a ser considerado na proximidade existente entre os idiomas português e espanhol é o geográfico. Portugal e Espanha, juntamente com Andorra e Gibraltar, compõem a Península Ibérica. Assim, ambos os idiomas sofreram as mesmas influências de outros invasores, destacando-se os árabes, que dominaram a região por aproximadamente oito séculos.

Quanto ao aspecto político, faz-se necessário destacar o período referente ao Domínio Filipino ou Dinastia Filipina. Entre 1580 e 1640, Portugal foi governado juntamente com a Espanha por Filipe II de Espanha e I de Portugal; Filipe III de Espanha e II de Portugal e Filipe IV de Espanha e III de Portugal. ${ }^{7}$

Tal fato foi possível porque naquela época era comum a ocorrência de casamentos entre nobres pertencentes às cortes portuguesa e espanhola. Dessa forma, havia portugueses que pertenciam à família real espanhola, ao mesmo tempo em que

\footnotetext{
$6 \quad$ Vale lembrar que a expansão das línguas neolatinas se deu a partir do latim vulgar, uma vez que o latim clássico era falado somente pelos nobres de Roma.

Filipe II de Espanha e I de Portugal, refere-se ao mesmo monarca e o mesmo se passa com Filipe III e com Filipe IV de Espanha, respectivamente. Tal fato se dá porque Filipe I de Espanha não governou Portugal.
} 
havia espanhóis que pertenciam à família real portuguesa. Durante esse período, Portugal e Espanha foram governados como se fossem um único país.

Quanto ao exposto anteriormente, Rodrigues (apud FIALHO, 2005) aponta que a distância entre os dois idiomas apenas foi mantida devido à independência política de Portugal e que essa distância é menor que as encontradas entre dialetos do italiano com a língua padrão ou mesmo do Vasco em relação ao Vasco padrão.

Outra constatação da proximidade entre os dois idiomas pode ser verificada em Carmolinga (apud FIALHO, 2005) que afirma que a maior semelhança entre as duas línguas se constata no léxico, visto que $85 \%$ das palavras possuem uma origem em comum.

Tais observações, reforçadas pelo posicionamento de Almeida Filho (apud ANDRADE NETA, 2007) que indica "que entre as línguas românicas o português e o espanhol são as que mantêm maior afinidade entre si” (tradução nossa), corroboram o objetivo deste trabalho que é propor uma metodologia fundamentada na Análise Contrastiva e na Análise de Erros, que aproveite o conhecimento do acadêmico em sua Língua Materna (LM) e que acelere o processo ensino-aprendizagem do espanhol.

\subsection{A Análise Contrastiva}

A Análise Contrastiva surgiu nos anos 60, em meio à vigência dos estudos estruturalistas e behavioristas, como uma metodologia que pudesse prevenir os erros cometidos em uma Língua Estrangeira estudada a partir da comparação entre os sistemas lingüísticos da LM e da LE.

Dessa forma, destacavam-se as semelhanças e as diferenças existentes entre os dois sistemas, com a finalidade de identificar os erros cometidos pelos aprendizes da LE, bem como as estruturas mais fáceis de serem adquiridas. "A Análise Contrastiva considerava que a principal fonte dos erros dos alunos era a transferência das estruturas e/ou traços da LM para a língua alvo.” (BARALO,1999, p.36) (Tradução Nossa).

Por outro lado, Vandressen (apud FIALHO, 2005) afirma que a função da Lingüística Contrastiva seria a de apontar as similaridades e diferenças estruturais entre a Língua Materna (LM) de um estudante e a Língua Estrangeira (LE) alvo; procurando, dessa forma, prever as estruturas que oferecem dificuldades de aprendizagem e as que apresentam facilidades. Assim, para Vandressen, a Análise Contrastiva é o resultado dos estudos realizados acerca da Lingüística Contrastiva.

Verifica-se, portanto, que a Análise Contrastiva está fundamentada no conceito de Interferência, uma vez que investiga a tendência do aprendiz de uma LE em substituir 
os traços fonológicos, morfológicos, sintáticos e lexicais dessa LE por aqueles encontrados em sua LM.

Percebe-se ainda que:

a "interferência" é manifestada através de "desvios" na Língua Estrangeira estudada, por influência da Língua Materna do aprendiz. Ou seja, o aprendiz tende a substituir traços fonológicos, morfológicos, sintáticos, (acrescentamos a estes os traços semânticos) da Língua Estrangeira pelos da Língua Materna. (VANDRESSEN apud SILVA, 2002)

Observa-se, porém, dentre as principais críticas recebidas pela Análise Contrastiva, que nem todos os erros cometidos pelos aprendizes de uma LE estão relacionados à Interferência da LM na LE. Outra crítica recebida pela Análise Contrastiva é que essa teria como foco principal a prevenção do erro e não o desenvolvimento da comunicação.

De qualquer forma, várias foram as contribuições proporcionadas pela Análise Contrastiva, uma vez que "o professor pode ajudar a criar um ambiente favorável no qual se desenvolva a língua na mente dos aprendizes, fomentando-a através do emprego adequado da Análise Contrastiva e da Análise de Erros" (DURÃO apud ANDRADE, 2002), (Tradução Nossa).

Quanto ao exposto anteriormente, faz-se importante observar que o contraste lingüístico envolvendo o idioma português e o espanhol pode auxiliar o aprendiz de um modo muito mais efetivo do que o que se pode observar no contraste envolvendo outro par de idiomas, já que de acordo com Espiga:

o caminho a percorrer, partindo do Português $(P)$ em direção ao Espanhol (E) é curto em distância, uma vez que, por serem línguas muito próximas na sua genealogia, são línguas também muito próximas na tipologia, com relativamente poucos estágios intermediários no aprendizado. (ESPIGA apud FIALHO 2005)

\subsection{A Análise de Erros}

A Análise de Erros surgiu a partir de determinadas críticas lançadas sobre a Análise Contrastiva. Trata-se de um método sustentado por estabelecimentos teóricos da lingüística chomskiana e das teorias cognitivas e mentalistas de aprendizagem.

Observou-se que muitos erros cometidos pelos alunos não estavam relacionados a um processo de transferência negativa da LM para a LE. Além disso, verificou-se a existência de uma considerável porcentagem de erros que não se podia atribuir ao processo de transferência. Desse modo, percebe-se que o erro faz parte do processo ensino-aprendizagem de uma LE. (BARALO, 1999). 
A partir da identificação dos erros, esses são classificados a fim de se perceber se os mesmos ocorrem ou não por interferência da LM.

Dentro dessa perspectiva, observa-se a constância com que o erro ocorre, e procura-se identificar as causas geradoras do equívoco. Os erros que ocorrem com menor intensidade podem ser, muitas vezes, considerados como frutos de um esquecimento ou de uma casualidade.

Por outro lado, os erros que ocorrem com maior freqüência podem demonstrar a interferência da LM na LE ou, ainda, a falta de domínio do aprendiz em relação às estruturas lingüísticas da língua alvo. Tais erros são, geralmente, chamados de erros sistemáticos. A literatura especializada aponta que as maiores interferências da LM na LE ocorrem justamente nas línguas mais próximas.

Diante do exposto anteriormente, faz-se oportuna a conscientização do professor quanto à necessidade de uma maior intervenção e correção dos erros a fim de se evitar que o aluno (aprendiz) permaneça estacionado na interlíngua por um largo período de tempo, uma vez que a progressão continuada do aluno deve ser uma das metas no ensino de um idioma estrangeiro.

O mais importante no processo de superação dos erros para evitar a sua fossilização é a tomada de consciência tanto por parte dos professores de E/LE que ensinam a brasileiros, como também por parte dos estudantes dessa língua, das peculiaridades do espanhol $\mathrm{e}$ das falsas semelhanças entre ambas as línguas. (ANDRADE NETA, 2006), (Tradução Nossa).

Quanto ao conceito de interlíngua, faz-se necessário esclarecer que o uso técnico desse termo generalizou-se a partir das propostas de Selinker (1972). O termo interlíngua refere-se, portanto, ao sistema lingüístico não nativo, ou seja, a uma língua (dialeto) por meio da qual o aprendiz de uma Língua Estrangeira se comunica, e não se refere nem a sua LM tampouco à LE a ser aprendida. Nesse caso, aponta-se o "portunhol" como sendo a interlíngua existente entre os idiomas português e espanhol.

Assim, a interlíngua pode ser vista sob duas perspectivas, uma positiva e outra negativa. O ponto positivo é que a interlíngua pode ser tomada como um sinal de progresso, uma vez que, apesar dos erros cometidos, o aprendiz já se comunica parcialmente na língua alvo. O ponto negativo trata da fossilização do erro, ou seja, da sua perpetuação, caso não haja correção do mesmo.

Essa fossilização dá-se, geralmente, quando o aprendiz acomoda-se na posição de usuário da interlíngua, julgando-a suficiente para manter seus atos comunicativos e a partir daí não mais procura progredir em seus estudos da LE. 
Dessa forma, torna-se claro que a proximidade existente entre os idiomas português e espanhol pode auxiliar no processo de aceleração do E/LE. Por outro lado, essa mesma proximidade pode ser a grande responsável por uma série de erros cometidos pelo aprendiz a partir da interferência da LM na LE. Foi, portanto, a partir dessa constatação que se julgou oportuno o ensino dos heterogenéricos, heterossemânticos e heterotônicos como aceleradores iniciais do processo ensino-aprendizagem.

\subsection{0 estudo dos heterogenéricos, heterossemânticos e heterotônicos}

Antes de se iniciar a apresentação do estudo acerca dos vocábulos heterogenéricos, heterossemânticos e heterotônicos considera-se importante estabelecer a distinção entre aquisição e aprendizagem.

De acordo com a distinção feita por S. Krashen, entende-se que a aquisição de um idioma é um processo espontâneo e inconsciente de internalização das regras, por meio da mera exposição natural, enquanto que a aprendizagem constitui um processo consciente que se dá por meio da instrução formal em sala de aula. (GARGALLO,1999).

A partir dessas definições, percebe-se que o estudante brasileiro que aprende o espanhol em seu próprio país não passa pelo processo de aquisição da Língua Estrangeira, uma vez que não tem a possibilidade de utilizar a LE no ambiente "extra classe". Esse fato justifica a utilização da LM durante os estudos da LE, uma vez que o estudante não se encontra em um sistema de imersão total na língua alvo.

\subsubsection{Os heterogenéricos}

Os heterogenéricos são substantivos que, na língua espanhola, têm gênero diferente do português (MILANI,2000, p. 47). Trata-se, portanto, de vocábulos que, em sua maioria, são idênticos ou semelhantes quanto à forma gráfica e ao significado e que, porém, divergem quanto ao gênero em relação ao outro idioma. Assim, encontram-se palavras cujo gênero é feminino em português e masculino em espanhol e vice-versa.

Considera-se importante a valorização do estudo desses vocábulos uma vez que a partir do seu conhecimento, o estudante poderá realizar, corretamente, suas próprias escolhas diante de determinadas construções no idioma espanhol. Para isso, fazse necessário que o professor demonstre ao aluno não apenas a identificação dos vocábulos heterogenéricos de modo isolado, mas, sim, de forma contextualizada.

Acredita-se que a explicação a respeito dos heterogenéricos deve ser seguida da apresentação dos casos especiais de uso dos artigos masculinos el / un + substantivo feminino existente no idioma espanhol, como forma de facilitar a aprendizagem e evitar futuros equívocos. 
De acordo com essa regra, empregam-se os artigos masculinos el / un diante de substantivos femininos singulares cuja silaba inicial seja formada por "a" ou "ha" tônicas, desde que não haja entre eles a interposição de qualquer palavra. Tal medida é utilizada a fim de se evitar a repetição de dois sons iguais. Dessa forma, evita-se a repetição do "a" final existente nos artigos femininos la / una e o "a" ou "ha" tônico no início da palavra subseqüente.

Assim o uso dos artigos masculinos "el’8 e "un" diante das palavras iniciadas com "a" ou "ha" tônicos permitem a elisão fonética.

Por meio da apresentação dessa regra, o aprendiz saberá identificar que nem todas as palavras precedidas pelos artigos masculinos el / un em espanhol são necessariamente masculinas. Porém, a melhor maneira de conscientizar o aluno dessa diferença está, sem dúvida, na demonstração de que o adjetivo que acompanha o substantivo indica o gênero do mesmo.

Desse modo, verifica-se que na frase: "el hada madrina" (a fada madrinha) o adjetivo madrina está no feminino, e, portanto, o artigo masculino "el" precede o substantivo feminino hada (fada) por uma questão de eufonia e não por se tratar de um substantivo masculino. Por outro lado, tomando-se a frase em espanhol: "el árbol florido" (a árvore florida), percebe-se que o adjetivo (florido) que acompanha o substantivo "árbol" (árvore) encontra-se no masculino, logo o substantivo "árbol" pertence ao gênero masculino na língua espanhola.

Outro fato importante que se pode ensinar aos alunos por meio da análise contrastiva entre o português e o espanhol está na relação estabelecida entre os substantivos espanhóis terminados em "aje". Os livros didáticos e as gramáticas trazem a informação de que esses são masculinos. Porém, a partir do contraste realizado com a língua portuguesa, o aluno perceberá que todos os substantivos que terminam em "aje" em espanhol, além de serem femininos na língua portuguesa, terminarão sempre em "agem", como o caso de: mensaje $(E)$ - mensagem $(P)$, paisaje $(E)$ - paisagem $(P)$ etc. Contudo, deve-se alertar aos aprendizes que nem todos os substantivos que terminam em "agem", em português, terão, em espanhol, a terminação "aje" e serão masculinos, por exemplo: a imagem - la imagen (também feminino em espanhol e terminado em "agen").

Acredita-se que intervenções como essas, além de outras que podem ser desenvolvidas pelo professor, permitem aos aprendizes um maior desenvolvimento em

\footnotetext{
$8 \quad$ Faz-se importante distinguir que o artigo masculino "el" que corresponde ao artigo definido "O" em português não é acentuado. Por outro lado, o pronome pessoal "él” (acentuado) corresponde em português ao pronome pessoal "ele".
} 
relação ao avanço na interlíngua e são capazes de evitar a fossilização de erros cometidos na LE por interferência da LM.

\subsubsection{Os heterossemânticos}

Os heterossemânticos são vocábulos muito semelhantes na grafia e na pronúncia do espanhol e do português. Porém, possuem significados diferentes em ambas as línguas.

Acredita-se na importância do estudo dos vocábulos heterossemânticos como forma de aceleração do processo de aprendizagem, uma vez que se trata do grupo de vocábulos chamados de falsos cognatos, ou ainda, "falsos amigos" e também por serem esses encontrados de forma abundante na relação entre os dois idiomas.

Embora possam apresentar semelhança gráfica e/ou fonológica, esses vocábulos são completamente distintos do ponto de vista semântico, podendo levar o aprendiz a cometer grandes erros de interpretação e, por conseqüência, podem dificultar a eficácia da compreensão.

Devido ao exposto anteriormente, pode-se assegurar que o grupo dos vocábulos heterossemânticos constitui-se em grande "ameaça" ao processo comunicativo, visto que é capaz de causar interferências significativas na comunicação.

Segundo Almeida Filho (apud FIALHO, 2005) "o léxico entre as duas línguas é constituído por $60 \%$ de cognatos idênticos e 30\% de cognatos falsos"(sic). Observa-se, portanto, que, durante o estudo da língua espanhola, o aprendiz irá deparar-se com uma infinidade de vocábulos que são "verdadeiros" cognatos, e o estudo dos heterossemânticos tem como objetivo prepará-lo para não tomar o falso por verdadeiro; melhorando, dessa forma, a sua capacidade comunicativa.

Os estudos de Andrade Neta (2007) apontam uma divisão na classificação dos heterossemânticos, proposta por Fernandez Bechara e Gustavo Moure. Assim, podem-se dividir os heterosemânticos em:

a- Formas semelhantes com significados completamente distintos: diz respeito aos vocábulos que apresentam forma semelhante ou idêntica em ambos os idiomas e que, porém, diferem totalmente quanto ao significado empregado em ambas as línguas. Assim, não oferecem nenhum significado comum nas línguas confrontadas, como, por exemplo: ambos os idiomas possuem a palavra "BERRO". Porém, o que se passa é que essa palavra em português significa soltar um grito, enquanto que em espanhol descreve uma hortaliça que tem como vocábulo equivalente em português o nome: agrião. 


\section{b- Formas semelhantes com um ou mais de um significado semelhante e outro}

ou vários outros distintos: os vocábulos pertencentes a esse grupo possuem um ou mais equivalentes, porém apresentam outro ou outros distintos, ou seja, sem correspondência no português e no espanhol. O vocábulo "ACORDAR", por exemplo, em ambas as línguas, apresenta o sentido de "estar de acordo". No entanto, apresenta significados muito diferentes em ambas as línguas, uma vez que em português também é sinônimo de "DESPERTAR-SE", enquanto que em espanhol é sinônimo dos vocábulos "DECIDIR, ACORDARSE" que em português significam "LEMBRAR-SE".

c- Formas semelhantes com significados distintos no uso atual: tratam-se dos vocábulos que possuem uma origem comum e que já chegaram a compartilhar, em fases anteriores, o mesmo significado nas duas línguas. Cita-se, por exemplo, a palavra latir originada do latim. Essa palavra significava "pulsar, latir" o coração e ao mesmo tempo descrevia o "ladrar" do cachorro. Deu-se, porém, que a língua portuguesa manteve para esse vocábulo apenas o sentido de "ladrar", que é o latir do cachorro, enquanto que em espanhol apenas se manteve o sentido de "latir, pulsar" que é o "bater" do coração.

Além disso, existe ainda um grande número de vocábulos heterossemânticos encontrados na relação entre os idiomas português e espanhol. Pode-se perceber, a partir da apresentação dos mesmos, a grande semelhança quanto à pronúncia e à escrita, assim como a diferença semântica existente entre esses vocábulos.

Diante dessas observações, acredita-se que o estudo dos heterossemânticos, no início do processo ensino-aprendizagem, pode colaborar de maneira substancial com o aprendiz a fim de se evitar equívocos de interpretação e, conseqüentemente, facilitar a capacidade de compreensão comunicativa.

\subsubsection{Os heterotônicos}

Os heterotônicos "são palavras com grafia semelhante em português e espanhol, mas que na pronúncia têm a sílaba tônica diferente." (MILANI,2000, p. 22). A autora ainda ressalta que há inúmeros casos de heterotonia entre as duas línguas.

Neste trabalho, propõe-se que o estudo dos heterotônicos seja precedido pelo estudo das regras de acentuação, que são encontradas em menor número no idioma espanhol que no português, principalmente em relação ao hiato. Tal proposição justificase pelo fato de que ao contrário da língua portuguesa, na qual todas as paroxítonas terminadas em ditongo são acentuadas; em espanhol não se acentuam as "graves ou Ilanas" (que correspondem às paroxítonas) terminadas em ditongo. 
Dessa forma, o aprendiz poderá ser levado a perceber com facilidade a diferença de tonicidade existente entre as palavras que nas duas línguas terminam em ditongo. Um bom exemplo para que o aprendiz possa identificar tal diferença consiste no par lingüístico apresentado abaixo:

\section{PORTUGUÊS}

Secretária

Secretaria

\section{ESPANHOL}

\section{Secretaria}

Secretaría

Percebe-se, pelo exemplo anterior, que, em português, as paroxítonas terminadas em ditongo são acentuadas, enquanto que, em espanhol, as "graves ou llanas", terminadas em ditongo, não se acentuam. Além disso, percebe-se que quando houver duas palavras de mesma grafia em ambos os idiomas, sendo elas terminadas em ditongo, sem que haja acentuação, a silaba tônica da palavra em espanhol será diferente daquela existente na palavra em português.

\section{PORTUGUÊS}

Elogio

Asfixia

\section{ESPANHOL}

elogio

asfixia

Acredita-se que o estudo dos vocábulos heterotônicos, bem como o estudo contrastivo das regras de acentuação, podem levar o aprendiz a desenvolver mais rapidamente a sua capacidade leitora e ortográfica, uma vez que poderá utilizar-se dos conhecimentos que já possui em sua LM e aplicá-los em relação à LE.

\section{CONSIDERAÇÕES FINAIS}

Embora o principal objetivo desse trabalho seja apontar o contraste entre as línguas portuguesa e espanhola como forma de desenvolvimento do falante do português do Brasil, aprendiz do idioma espanhol, pela possibilidade de se aproveitar o conhecimento que este possui em sua LM, faz-se extremamente necessário reconhecer que não se pretende colocar essa como a única metodologia a ser utilizada pelo professor a fim de atingir os objetivos estabelecidos quanto ao ensino do idioma espanhol.

Reconhece-se a existência de diversas metodologias que se preocupam em possibilitar ao estudante de uma LE o melhor aproveitamento possível quanto ao que diz respeito às habilidades necessárias à comunicação. Apesar de algumas metodologias privilegiarem algumas habilidades em detrimento de outras, sabe-se que interessa a todo aprendiz de uma LE desenvolver as habilidades: oral, escrita, leitora e auditiva. 
Por outro lado, entende-se que qualquer metodologia que queira encerrar o assunto, reservando apenas para si a condição de capacitar de forma completa todos os indivíduos que se proponham a aprender um novo idioma, será, no mínimo, tachada de pretensiosa.

Isso não apenas pelo fato de que a literatura especializada consiga apontar pontos positivos e negativos em relação a todas as metodologias apresentadas para 0 ensino de uma LE; mas, também, pela complexidade existente em relação ao sujeito aprendiz.

No entender de Leffa:

Nenhuma abordagem contém toda a verdade e ninguém sabe tanto que não possa evoluir. A atitude sábia é incorporar o novo ao antigo; o maior ou menor grau de acomodação vai depender do contexto em que se encontra o professor, de sua experiência e de seu nível de conhecimento. (LEFFA, 1988, p. 230).

Cada indivíduo, como se sabe, constitui um sistema complexo. Há alunos que são mais auditivos, outros visuais, outros sinestésicos. Desse modo, o professor de um idioma estrangeiro deve conhecer essa realidade e desenvolver atividades que atendam a cada um dos tipos de sujeito aprendiz.

Quanto a isso, Gargallo sinaliza para o seguinte:

Defendemos a idéia de que o professor de espanhol como língua estrangeira deve ter uma formação completa, que inclua os fundamentos teórico-práticos das distintas orientações metodológicas, o manejo dos materiais didáticos, assim como a capacidade para adaptá-los e criar outros novos. (GARGALLO, 1999, p. 82) (Tradução e grifo nossos)

Assim, percebe-se pela afirmação de Gargallo que cabe ao professor de uma LE identificar as reais necessidades dos aprendizes e aplicar os recursos visuais, auditivos, de leitura e de compreensão textual, etc., propostos pelas diferentes metodologias, de acordo com a finalidade que se pretenda atingir, considerando sempre as condições dos alunos.

Por isso, propõe-se nestas páginas a utilização da Análise Contrastiva e da Análise de Erros, bem como o estudo dos heterogenéricos, heterossemânticos e heterotônicos no início do processo ensino-aprendizagem do idioma espanhol por parte dos estudantes brasileiros.

Tal proposição reforça-se ainda mais a partir da realidade dos estudantes que estão aprendendo o E/LE em seu país, ou seja, no Brasil, pois como foi dito anteriormente, esses estudantes não tem acesso ao processo de aquisição do idioma estrangeiro que se dá de forma natural, estando sujeitos apenas ao processo de aprendizagem que se dá somente no ambiente de sala de aula. Essa é a razão 
fundamental pela qual se preconiza a utilização do contraste entre a LM e a LE a ser aprendida.

Outra importante consideração em relação às críticas que possam ser feitas em relação ao contraste entre dois idiomas é justamente o fato de que a grande maioria daqueles que teceram críticas tanto à Análise Contrastiva quanto à Análise de Erros eram pensadores cujo idioma nativo era o inglês. Sabe-se que o inglês não possui tantas semelhanças em relação a outro idioma, assim como as que existem entre o português e o espanhol.

Quanto ao estudo dos heterogenéricos, heterossemânticos e heterotônicos, acredita-se que:

- o estudo dos heterogenéricos, no início do processo ensino-aprendizagem, seja capaz de proporcionar ao aprendiz a capacidade de eliminar o auto índice de interferência da LM sobre a LE, possibilitando ao estudante a condição de construir sentenças corretas com maior segurança;

- o estudo dos heterossemânticos seja capaz de possibilitar ao aprendiz a identificação dos falsos cognatos, o que por sua vez permitirá uma maior compreensão textual e conseqüente desenvolvimento em relação ao idioma espanhol;

- o estudo dos heterotônicos, junto ao estudo contrastivo das regras de acentuação, seja capaz de desenvolver no estudante uma melhoria em sua habilidade leitora e, por conseqüência, em sua capacidade de escrita, visto que muitas palavras existentes nos dois idiomas possuem a mesma grafia, embora tenham diferentes sílabas tônicas.

Esses são, pois, de forma resumida, alguns dos motivos pelos quais se propõe o estudo desses vocábulos como forma de aceleração do processo ensino-aprendizagem.

Além disso, faz-se importante ressaltar que a grande maioria dos livros e gramáticas destinados ao ensino do idioma espanhol para brasileiros traz em seu conteúdo o estudo desses vocábulos; o que, por si só, demonstra a importância dos mesmos para tais aprendizes.

Claro é, também, que o ensino de um idioma não se resume à apresentação de pontos gramaticais, sendo necessária a apresentação de outros pontos relativos à cultura, à história, à geografia, à literatura, entre outros aspectos que digam respeito ao povo ou aos povos que falam o idioma estrangeiro a ser estudado. Além disso, entende-se que a partir do momento em que o aluno tenha capacidade de ler, escrever e compreender o 
que lê, mais rapidamente, maior será sua chance de desenvolver-se em relação a esse idioma.

Outro ponto que se pretende abordar retoma a afirmação já exposta de Almeida Filho (apud FIALHO, 2005), na qual o autor aponta que "o léxico entre as duas línguas é constituído por $60 \%$ de cognatos idênticos". Dessa forma, pode-se inferir que o estudante não pode ser considerado um iniciante, visto que encontrará grande parte das palavras que já conhece inseridas no outro idioma, necessitando apenas "ajustar" a pronúncia, em alguns casos, para que essa seja inteligível no outro idioma. Porém, cabe dizer que somente por meio do contraste entre os dois idiomas é que o aprendiz terá acesso a essa informação, visto que o estudante não a possui previamente.

Por fim, aponta-se que este trabalho não pretende criticar aqueles que ensinam o espanhol a estudantes brasileiros utilizando-se para isso apenas do idioma alvo. Ao contrário, pretende estabelecer um modelo que atenda a realidade dos nossos estudantes dentro de um modelo bilateral, visto que, tanto para o estabelecimento das diferenças quanto para o das semelhanças, caberá ao estudante avançar nos estudos tanto da LM quanto da LE.

\section{REFERÊNCIAS}

ANDRADE, Otávio Goes de. A conjugação dos modelos de análise contrastiva e de análise de erros no tratamento dos matizes do verbo português ficar em espanhol. In: CONGRESO BRASILENO DE HISPANISTAS, 2., 2002, San Pablo. Anales electrónicos... Associação Brasileira de Hispanistas, Disponible en: $<$ http://www.proceedings.scielo.br/scielo.php?script=sci_arttext\&pid=MSC0000000012002 000100048\&Ing=es\&nrm=abn>. Aceso en: 18 Mar. $200 \overline{7}$.

ANDRADE NETA, Nair Floresta. 2006. In: Es fácil hablar español porque hablo portugués. Disponível em: <http://www.cuadernoscervantes.com/lc_portugues.html>. Acesso em: 08 abr. 2007

BARALO, Marta. La adquisición del español como lengua extranjera. Madrid: Arcos libros. 1999. 72 p.

BRASIL. Ministério da Educação e Cultura. MEC participa de congresso colombiano que discute ensino do espanhol. [ Brasília, DF ] Disponível em: $<$ http://portal.mec.gov.br/ai/index.php?option=content\&task=view\&id=6679\&FlagNoticias= 1\&ltemid=6829. . Acesso em: 05 abr. 2007. 
FIALHO, Vanessa Ribas. Espéculo. Revista de estudios literarios. 2005. Universidad Complutense de Madrid EI URL de este documento es

<http://www.ucm.es/info/especulo/numero31/falantes.html> Acesso em: 06 abr. 2008.

FREIRE, M. Teodora Rodríguez Monzú. Síntesis gramatical de la lengua española Una gramática contrastiva Español - Portugués. 5. ed. São Paulo: Enterprise Idiomas. 1999. $152 \mathrm{p}$.

GARGALLO, Isabel Santos. Lingüística aplicada a la enseñaza-aprendizaje del español como lengua extranjera. Madrid: Arcos libros. 1999. 95 p.

LEFFA, Wilson J. Metodologia do ensino de línguas. In BOHN, H. L.; VANDRESSEN. $P$. Tópicos em lingüística aplicada: $O$ ensino de línguas estrangeiras. Florianópolis. Ed. da UFSC. 1988. p. 211- 236.

MILANI, Esther Maria. Gramática de espanhol para brasileiros. 2. ed. São Paulo: Saraiva. 2000. 384 p.

SILVA, Eliane Barbosa da. Bloqueios do aprendiz de espanhol/LE: Os heterossemânticos. In: CONGRESO BRASILENO DE HISPANISTAS, 2., 2002, San Pablo. Anales electrónicos... Associação Brasileira de Hispanistas, Disponible en: <http://www.proceedings.scielo.br/scielo.php?script=sci_arttext\&pid=MSC0000000012002 000100020\&lng=es\&nrm=abn>. Aceso en: 18 Mar. $200 \overline{7}$. 